\title{
Study the Effect of Cold Plasma on the Structure and Surface Properties of PbO Thin Film
}

\author{
Dr. Ramiz Ahmed Mohammed ${ }^{1}$, Dr. Hamid Hafidh Murbat ${ }^{2}$, Shaymaa Ibrahimm Ahmood ${ }^{3}$ \\ ${ }^{1}$ University of Baghdad, Collage of Science for Women, Department of Physics, Al Mansour, Baghdad, Iraq \\ ${ }^{2}$ University of Baghdad, Collage of Science for Women, Department of Physics, Baghdad, Iraq \\ ${ }^{3}$ University of Baghdad, Collage of Science for Women, Department of Physics, Palestine Street, Baghdad, Iraq
}

\begin{abstract}
In this research, the structural and surface property of lead oxide thin films (PbO) has been studied. They were prepared by the chemical Spray Pyrolysis method on glass substrates at $\left(450^{\circ} \mathrm{C}\right)$.the structural properties has been studied using $X$-ray diffraction (XRD) analysis and the surface properties of the thin film where investigated using atomic force microscopy AFM analysis before and after the subjection of the thin film to cold plasma at different times $(5,10,15,20,25)$ min. dielectric barrier discharge system were used to generate the cold plasma. The results of (XRD) tests showed that all the prepared films were of a polycrystalline and the thickness of the thin film is slightly decreases when subjected to cold plasma and the average of crystal size rates increasing too. The pictures of atomic force microscope (AFM) showed the values of the average of the surface roughness and the square root (RMS) increases as time of treatment increase
\end{abstract}

Keywords: lead oxide, chemical spray pyrolysis, structural properties, surface properties, cold plasma

\section{Introduction}

Thin film technology is one of the most important technologies that contributed to the development of the semiconductor study. It gave a clear idea of many of its physical and chemical properties, and it differs from the material in its bulk condition. It is not completely dense and has different defect structures. The thin membrane is defined as a layer of layers of material atoms the thickness of one micron [1], [2]

The study of thin films has attracted the attention of many researchers since the nineteenth century, as there has been a lot of important research in this area.

The term thin films are used to describe one or several layers of atoms of a specific material that does not exceed several microns. The thickness of thin films is easy to crack, resulting in their deposition on different materials depending on the nature of the study such as glass, quartz and silicon.

Plasma is defined as a semi-neutral gas of charged and neutral particles that exhibit collective behavior [6], [5]. Plasma is classified into two main categories: high temperature plasma (plasma fusion) and low temperature plasma (gas discharge) or non-thermal plasma [7]

Non-thermal plasma is the state of which ions and neutral particles have the same temperature surrounding them, but the temperature of electrons is much higher. Most of the energy processed in the cold plasma turns into electrons in the plasma, thus producing effective electrons instead of heating the gas in general. Ions and neutral particles are relatively cold. They have been used in the treatment of thermally sensitive materials, including polymers and biologics [8], and in various industrial and scientific applications. [9] And tissue [10]. The plasma has been generated by the barrier technique (DBD), which is widely used in a large number of industrial applications and technology. It is characterized by the other types of discharge that it works for the production of non-thermal plasma at atmospheric pressure. This technique is used in the applications of surface treatment [11]

A thin membrane of lead oxides $(\mathrm{PbO})$ was introduced and exposed to non - thermal plasma at different times and studied the nature of the surface after treatment. XRD and AFM were used in studying the changes that occur on surface of the membranes.

\section{Experimental}

\section{A. Sample preparation and deposition procedure}

The $\mathrm{PbO}$ thin films were prepared by spraying an aqueous solution of Lead (II) acetate trihydrate. This solution of $0.1 \mathrm{M}$ was prepared by dissolving $1.899 \mathrm{gm}$ of $\mathrm{Pb}(\mathrm{CH} 3 \mathrm{COO}) 2.3 \mathrm{H} 2 \mathrm{O}$ [which is a powder of white color, it's molecular weight $(379.33 \mathrm{~g} / \mathrm{mol})]$ in $50 \mathrm{ml}$ distilled water. The weights of $[\mathrm{Pb}(\mathrm{CH} 3 \mathrm{COO}) 2.3 \mathrm{H} 2 \mathrm{O}]$ were measured by using sensitive electrical balance of four digits (10-4 g).the solutions was mixed with magnetic stirrer for 10-15 min to complete the dissolving process and left for 1 hour to get a homogenous solution at temperature of $450{ }^{\circ} \mathrm{C}$. Using the spray pyrolysis method to prepare the thin film on a glass base the durance time to spray was $5 \mathrm{sec}$ and then stop for $55 \mathrm{sec}$. when the drop of solution reach the hot solid surface the water evaporate and the reaction occur to form the $\mathrm{PbO}$ thin film

\section{B. Treatment with Cold Plasma}

Dielectric barrier discharge system consist of two cylindrical electrode made of cupper with diameter $(50 \mathrm{~mm})$, the electrode was surrounding by Teflon with thickness $(10 \mathrm{~mm})$. The two electrodes were fixed such that one of them can be 


\section{International Journal of Science and Research (IJSR) \\ ISSN (Online): 2319-7064}

Index Copernicus Value (2015): 78.96 | Impact Factor (2015): 6.391

moved vertically to change the distance between the electrodes. The two electrodes were connected to high power Ac voltage. One of the electrodes was covered by dielectric material. The instrument is shown in figure

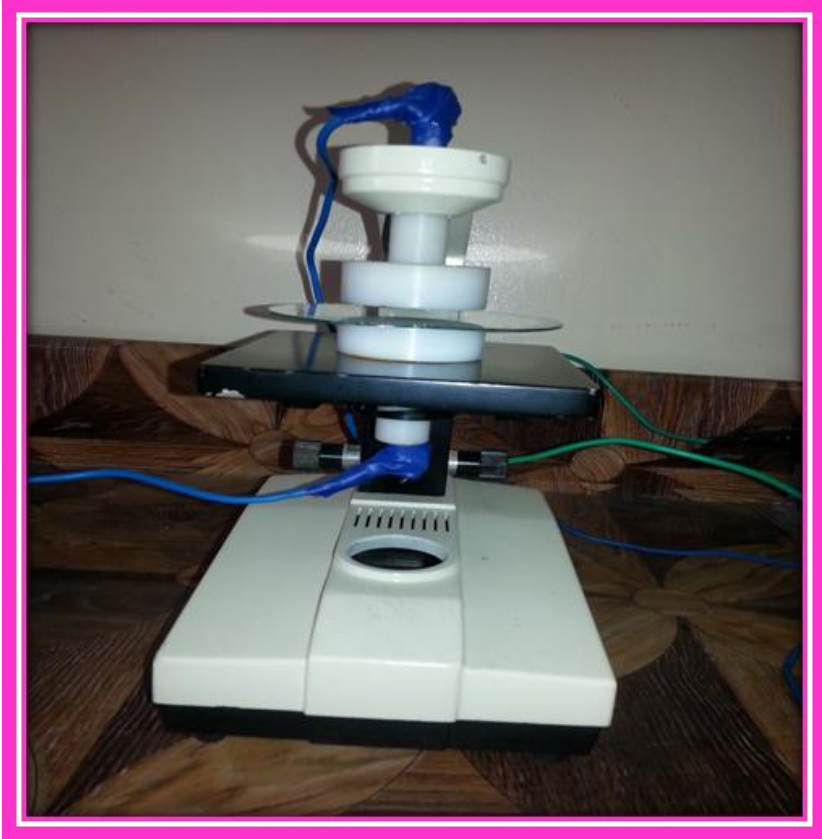

Figure 1: Dielectric barrier discharge system

The $\mathrm{PbO}$ thin films were placed between the two electrode which they were departed at distance of $2 \mathrm{~mm}$ and the plasma were generated at $\mathrm{AC}$ voltage ....... The thin films were subjected to the cold plasma at different times $(5,10,15,20$, 25) min. After the treatment the samples were taken for XRD and AFM analysis

\section{Results and Discussions}

\section{A. XRD result}

The X-ray Diffraction investigation has been carried out for thin films $(\mathrm{PbO})$ as shown in Fig. (2), for range of $2 \theta$ from $15^{\circ}-75^{\circ}$. According to phase identification software (Match!), the prepared thin film sample has the sample diffraction pattern of reference[10]the rest of the matched data are shown in figure (3) such as the cell parameters $\mathrm{a}=\mathrm{b}=$ $3.9748 \AA$ and $\mathrm{c}=5.0227 \AA$. the structure of these films showed a polycrystalline structure with crystal system of tetragonal. The interplanner spacing (dhk1) was determined using the Bragg relationship [62].

$$
2 \mathrm{~d} \sin \theta=\mathrm{n} \lambda
$$

Where $\mathrm{n}$ is an integer that indicates the order of the reflection, $\theta$ is Bragg angle, and $\lambda$ is the wavelength of the $\mathrm{X}$ ray beam.

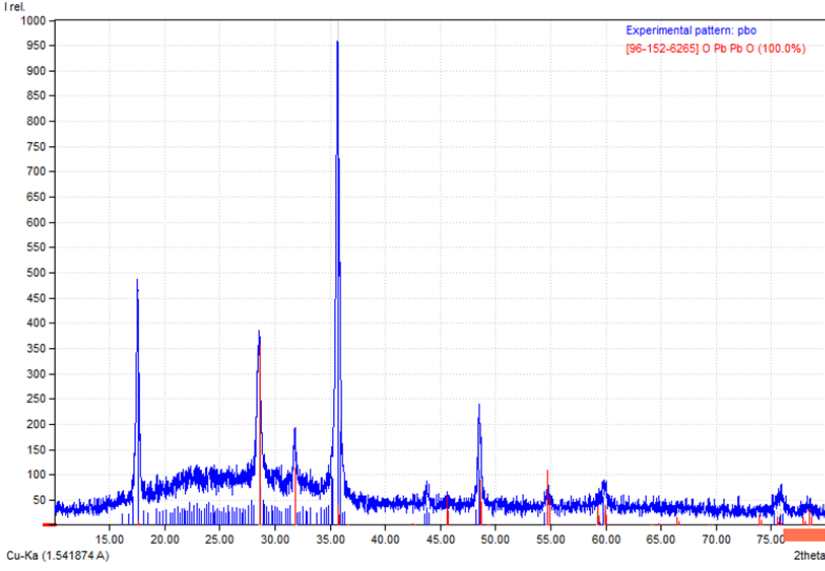

Figure 2: XRD of the prepared thin film (the blue peak) and the reference peak (the red line)

\begin{tabular}{|c|c|c|c|}
\hline \multirow{2}{*}{\multicolumn{4}{|c|}{ Sample Data }} \\
\hline & & & \\
\hline \multicolumn{3}{|c|}{ Data range } & $9.950^{\circ}-79.950^{\circ}$ \\
\hline \multicolumn{3}{|c|}{ Number of points } & 3501 \\
\hline \multicolumn{3}{|c|}{ Step size } & 0.020 \\
\hline \multicolumn{3}{|c|}{ Rietveld refinement converged } & No \\
\hline \multicolumn{3}{|c|}{ Apha2 subtracted } & No \\
\hline \multicolumn{3}{|c|}{ Background subtr. } & No \\
\hline \multicolumn{3}{|c|}{ Data smoothed } & No \\
\hline \multicolumn{3}{|c|}{ 2theta correction } & $-0.05^{\circ}$ \\
\hline \multicolumn{3}{|c|}{ Radiation } & X-rays \\
\hline \multicolumn{3}{|c|}{ Wavelength } & $1.541874 \mathrm{~A}$ \\
\hline \multirow{2}{*}{$\underset{\mathrm{A}}{\text { Index }}$} & Amount $(\%$ & $\mathrm{Nam}$ & \\
\hline & $\begin{array}{c}100.0 \\
37.7\end{array}$ & $\begin{array}{l}\mathrm{Pb} O \\
\text { Unid }\end{array}$ & ed peak area \\
\hline \multicolumn{4}{|c|}{$A: P b O(100.0 \%)$} \\
\hline \multicolumn{3}{|c|}{ Formula sum } & $\mathrm{OPb}$ \\
\hline \multicolumn{3}{|c|}{ Entry number } & $96-152-6265$ \\
\hline \multicolumn{3}{|c|}{ Figure-of-Merit (FoM) } & 0.815279 \\
\hline \multicolumn{3}{|c|}{ Total number of peaks } & 68 \\
\hline \multicolumn{3}{|c|}{ Peaks in range } & 42 \\
\hline \multicolumn{3}{|c|}{ Peaks matched } & 20 \\
\hline \multicolumn{3}{|c|}{ Intensity scale factor } & 0.36 \\
\hline \multicolumn{3}{|c|}{ Space group } & $\mathrm{P} 4 / \mathrm{n} \mathrm{m} \mathrm{m}$ \\
\hline \multicolumn{3}{|c|}{ Crystal system } & tetragonal \\
\hline \multicolumn{3}{|c|}{ Unit cell } & $a=3.9748 A c=5.0227 \mathrm{~A}$ \\
\hline \multicolumn{3}{|c|}{ V/c } & 28.83 \\
\hline \multicolumn{3}{|c|}{ Calc. density } & $9.339 \mathrm{~g} / \mathrm{cm}^{3}$ \\
\hline
\end{tabular}

Figure 3: XRD measuring condition and property data of the sample

From the study of the X-ray diffraction pattern and locating the position of the peak as shown in figure 4. After the subjection of the thin film to cold plasma at different times $(5,10,15,20,25) \mathrm{min}$. It has notice that the peak 002 at 5 min of subjection to the cold plasma has intensity of 1500 , but when the treatment time increases to $10 \mathrm{~min}$ the intensity of the same peak decreases to 1400 , when the time increase to $15 \mathrm{~min}$ the intensity decreases to 1200 . at subjection time of 20 the intensity was 1100 and at 25 the intensity was 900.for the second peak of 001 there is no significant effect at treatment time of 5 and $10 \mathrm{~min}$ and the effect is shown after $15 \mathrm{~min}$ of treatment at intensity value of 500 and at 25 min of treatment the intensity decreases to 400 . For the rest of the peaks there is no significant change at any time of treatment. 
International Journal of Science and Research (IJSR)

ISSN (Online): 2319-7064

Index Copernicus Value (2015): 78.96 | Impact Factor (2015): 6.391

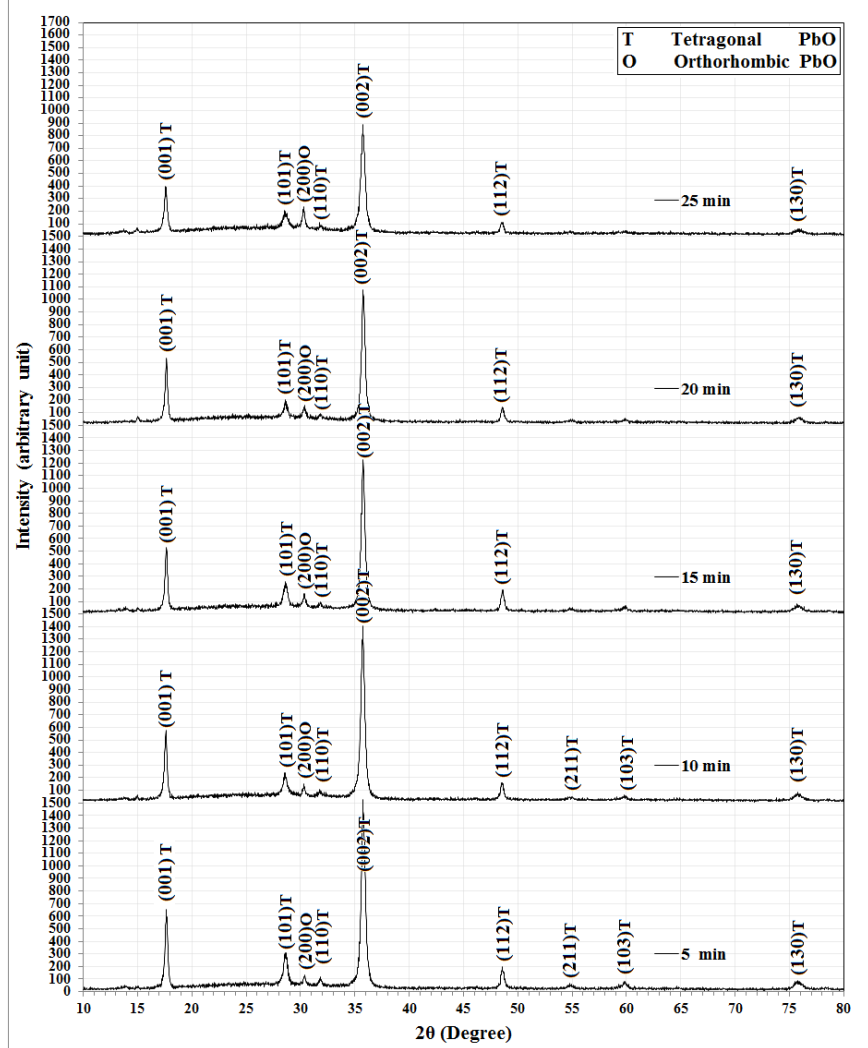

Figure 4: XRD of the thin film after the subjection of the thin film to cold plasma at different times

For all films, the grain size (G.S) was calculated from the full width at half maximum (FWHM) by using the DebyeSherrer, s equation [64].

$\mathrm{D}$ : The average grain size

$$
\mathrm{D}=\frac{0.94 \lambda}{\beta \cos \theta}
$$

$\lambda$ : is the X-ray wavelength $(\AA)$

$\beta$ : FWHM (radian).

$\theta$ : Bragg diffraction angle of the XRD peak (degree)

The grain size (G.S) was calculated using match! Software for the lead oxide $(\mathrm{PbO})$ thin film after the treatment with cold plasma at different times $(5,10,15,20,25) \mathrm{min}$ for the peak [(001), (200), (110), (112),(101),(130)].table 1 show the treated thin film at different time with the grain size, at 5 min of treatment the grain size was A 1906.4 and after 10 min treatment the grain size was $670.3 \mathrm{~A}$. at $15 \mathrm{~min}$ there is increase in the grain size at value of $3368.4 \mathrm{~A}$. the grain size continue to increase at 15 min treatment at value of $4045.6 \mathrm{~A}$ and at $25 \mathrm{~min}$ the grain size was $4275.4 \mathrm{~A}$.

Table 1: FWHM and Ave crystallite size calculation

\begin{tabular}{|c|c|c|c|c|}
\hline $\begin{array}{c}2 \text { theta } \\
\text { [deg] }\end{array}$ & I/IO & FWHM & $\begin{array}{c}\text { Ave Crystallite } \\
\text { size [A] }\end{array}$ & $\begin{array}{c}\text { Time } \\
\text { min }\end{array}$ \\
\hline 30.217 & 52.4 & 0.1547 & & \multirow{2}{*}{5} \\
\cline { 1 - 4 } 31.709 & 27.6 & 0.0437 & & \\
\hline 34.69 & 21.1 & 0.0266 & 1906.4 & \\
\hline 35.638 & 1000 & 0.0219 & & \multirow{2}{*}{10} \\
\hline 30.313 & 194.5 & 0.2272 & & \\
\hline 31.835 & 36.4 & 0.1224 & 670.3 & \\
\hline 34.749 & 38.6 & 0.1063 & & \\
\hline
\end{tabular}

\begin{tabular}{|c|c|c|c|c|}
\hline 35.765 & 1000 & 0.1028 & & \\
\hline 30.368 & 79.8 & 0.1429 & & \multirow{4}{*}{15} \\
\hline 31.858 & 32.8 & 0.0423 & 3368.4 & \\
\hline 34.782 & 3.6 & 0.0084 & & \\
\hline 35.024 & 3.2 & 0.1659 & & \\
\hline 30.368 & 44.6 & 0.1429 & & \multirow{4}{*}{20} \\
\hline 31.823 & 34.4 & 0.0425 & & \\
\hline 34.56 & 15.2 & 0.0272 & 4045.6 & \\
\hline 35.764 & 1000 & 0.0227 & & \\
\hline 30.357 & 83.6 & 0.0123 & & \multirow[b]{4}{*}{25} \\
\hline 31.83 & 25.1 & - & & \\
\hline 34.65 & 15.1 & 0.0268 & 4275.4 & \\
\hline 35.762 & 1000 & 0.0227 & & \\
\hline
\end{tabular}

\section{B. AFM result}

The study of topography of the lead oxide thin film $\mathrm{PbO}$ is accomplished by using atomic force microscopy (AFM) device. The AFM image were taken to the thin film after the subjection of the thin film to cold plasma at different times $(5,10,15,20,25)$ min. (Root Mean Square) (RMS) and (Roughness, Sq) are the two parameter that have been considered to study the change in roughness of the thin film after the treatment with cold plasma. Figure 4 Which show the relation between the time of cold plasma treatment both rouphness parameter $\mathrm{Sq}$ and RMS, as the treatment time of the cold plasma increase the roughness parameter also increase and the largest increment of the roughness start after 20 min of treatment. The result of the AFM also show the average diameter of the thin film as shown in the table 2 . The average diameter increase as the time of the treatment increase this behavior is similar to the XRD analysis where the average crystilinty size increase too

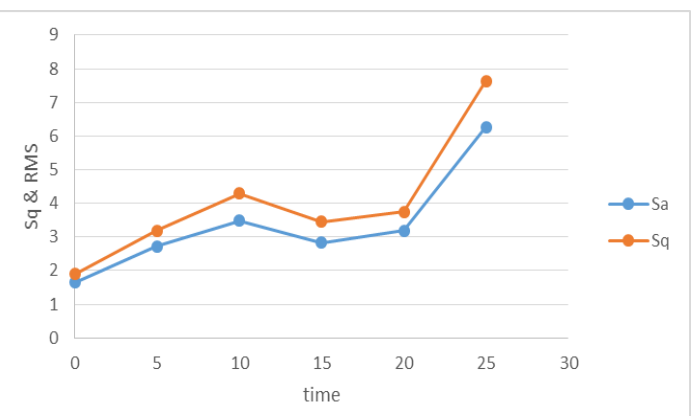

Figure 4: (Root Mean Square) (RMS) and (Roughness, Sq) VS time

Table 1: (Root Mean Square) (RMS) and (Roughness, Sq) at different times of treatment

\begin{tabular}{|c|c|c|c|}
\hline time & Sq & RMS & Avg. diameter nm \\
\hline 0 & 1.65 & 1.9 & 93.62 \\
\hline 5 & 2.72 & 3.19 & 99.56 \\
\hline 10 & 3.49 & 4.29 & 126.64 \\
\hline 15 & 2.83 & 3.45 & 97.57 \\
\hline 20 & 3.19 & 3.75 & 101.18 \\
\hline 25 & 6.26 & 7.63 & 109.1 \\
\hline
\end{tabular}

\section{Consolation}

Dielectric barrier discharge is one of the instrument that used to generate cold plasma for the surface modification application. The XRD data has shown that the decrease in the intensity as time of treatment increase indicate a removal of a

Volume 6 Issue 7, July 2017 www.ijsr.net 
very thin layer from the surface of the thin film. The AFM analysis show an increase in the surface roughness as treatment time increase also shows increase in the average diameter of which this behavior is similar to the grain size calculation of the XRD data.

\section{References}

[1] K. L. Chopra, "Thin Films Phenomena", MCGraw-Hill, New York (1969)

[2] K.D.L eaver and B.N.Champan, "Thin Films",Wykeham pubs., London(1971).

[3] F.F. Chen "Introduction to Plasma Physics and Controlled Fusion" ,Plenum Press, New York. (1984) .

[4] Janathan. Eastwood, Basic plasma physics, Imperial college London, (2013) .

[5] V. Nehra, A.Kumar, H.K.Dwivedi, Atmospheric NonThermal Plasma Sources ,International Journal of Engineering, 2, (2008), (53-68) .

[6] T.P. Kasih , Development of novel potential of plasma polymerization techniques for surface modification, dissertation submitted to graduate school of engineering Gunma University for degree of doctor of Engineering, (2007) .

[7] R.E.J.Sladek, Plasma needle non-thermal atmospheric plasmas in dentistry, Thesis submitted to doctor for Technische Universiteit Eindhoven, Netherlands Organization for Scientific Research (NWO) (2006) .

[8] Fridman G, Peddinghaus M, Ayan H, Fridman A, Balasubramanian M, Blood Coagulation and Living Tissue Sterilization by Floating-Electrode Dielectric Barrier Discharge in Air Plasma Chemistry and Plasma Processing 26, (2006) (425-442).

[9] H. W. Herrmann, I. Henins, J. Park and G. S. Selwyn. "Decontamination of Chemical and biological Warfare (CBW) agents using an atmospheric pressure plasma jet ",Physics of Plasmas, 6, (1999), (2284-2289) .

[10] Pirovano, C., Islam, M. S., Vannier, R. N., Nowogrocki, G. and Mairesse, G., 2001. Modelling the crystal structures of Aurivillius phases. Solid State Ionics, 140 (1-2), pp. 115-123. [12]- C.Kittle,"Introduction to solid state physics ", 6th .ed., John Wiley and Sons, New York, (1989).

[11] S. M. Sze, "Physics of Semiconductor Devices", John Wiley and Sons ,(1981).

[12] M. Nobial , O. Devos, and B. Tribollet, Proceeding of the International Workshop, " Advanced Techniques for Energy Sources Investigations and Testing ", Sofia , Bulgaria, Sep. (2001) .

Volume 6 Issue 7, July 2017 www.ijsr.net 